\title{
Jurnal

\section{EFEKTIFITAS SENAM KAKI TERHADAP NILAI ANKLE BRACHIAL INDEX PADA PENDERITA DIABETES MELLITUS TIPE 2}

\section{The Effectiveness of Foot Gymnastics on the Value of Ankle Brachial Index in Type 2 Diabetes Mellitus Patients}

\section{Made Mahaguna Putra, Ida Ayu Mas Narayani, I Komang Gde Trisna Purwantara, Ni Made Dwi Yunica Astriani}

1. STIKES Bu;eleng Bali

\section{Riwayat artikel}

Diajukan: 20 Juli 2019

Diterima: 28 Maret 2020

Penulis Korespondensi:

- Made Mahaguna Putra

- STIKES Buleleng Bali md.mahagunaputra@g mail.com

Kata Kunci:

Senam Kaki, Ankle

Brachial Index, DM Tipe 2
Abstrak

Pendahuluan: Salah satu komplikasi DM yaitu gangguan pada peredaran darah. Cara yang dapat dilakukan untuk mencegah gejala komplikasi tersebut yaitu degan terapi nonfarmakologi senam kaki. Senam kaki merupakan kegiatan latihan fisik mencegah komplikasi dan efektif untuk meningkatkan peredaran darah. Metode: Metode penelitian menggunakan pendekatan pre eksperimental design dengan rancangan one group pretest posttest design. Sampel terdiri dari 54 responden. Teknik sampling yang digunakan adalah non probability sampling yaitu purposive sampling, pengumpulan data menggunakan lembar observasi pengukuran nilai $\mathrm{ABI}$. Hasil: Hasil uji statistic Paired T-Test didapatkan nilai $\mathrm{p}=0,001$ yang berarti ada pengaruh Senam Kaki Terhadap Nilai Ankle Brachial Index Pada Penderita DM Tipe 2 Di Wilayah Kerja Puskesmas Banjar II. Diskusi: Dari hasil penelitian, ditemukan bahwa semakin bertambahnya usia semakin beresiko mengalami gangguan pada peredaran darah. Dimana responden dengan usia lanjut berada pada kategori penyakit vaskuler sedang.

Abstract
Introduction: One complication of DM is a blood circulation disorder.
Ways that can be done to prevent symptoms of complications are non-
pharmacological therapy offoot gymnastics. Foot gymnastics is a physical
exercise activity that prevents complications and is effective in increasing
blood circulation. Method: The research method used the pre-
experimental design approach with the design of the one group pretest-
posttest design. The sample consisted of 54 respondents. The sampling
technique used is nonprobability sampling, namely purposive sampling,
collecting data using observation sheets measuring the value of ABI.
Results: The results of the Paired T-Test statistical test obtained a value
of p = O.001, which means that there is an effect of Foot Gymnastics
Against the Value of Ankle Brachial Index in Patients with Type 2 DM in
the Work Area of Banjar II Health Center. Discussion: From the results
of the study, it was found that the more age increases the risk of developing
circulatory disorders. Where respondents with advanced age are in the
category of moderate vascular disease.




\section{PENDAHULUAN}

Prevalensi DM meningkat diakibatkan banyaknya pasien DM yang belum mendapat pengobatan maupun yang sudah mendapat pengobatan namun kadar gula dalam darahnya belum mencapai target normal serta adanya komplikasi yang dialami oleh pasien. (Fatimah, 2015).

Menurut WHO angka kejadian DM pada tahun 2015 sebanyak 415 juta orang dewasa dan pada tahun 2040 diperkirkan meningkat menjadi 642 juta kasus (WHO, 2016). Di Indonesia pada tahun 2018 didapatkan penderita sebanyak 8,1\%. (Kemenkes, 2018). Provinsi Bali menduduki urutan ke-19 penduduknya berusia $\geq 15$ tahun menderita penyakit tidak menular DM, yaitu $\geq 1 \%$ pada tahun 2015 (Kemenkes, 2018).

Hasil studi pendahuluan bulan November 2018 di Puskesmas Banjar II menunjukkan data penderita DM meningkat. Pada tahun 2017 jumlah penderita sebanyak 65 orang dan meningkat sampai bulan November tahun 2018 yaitu 72 orang. Setelah dilakukan wawancara dan observasi kepada 5 orang penderita DM tipe 2, didapatkan hasil 1 orang dengan kategori ABI normal, 2 orang dengan kategori $\mathrm{ABI}$ ringan, 2 orang dengan $\mathrm{ABI}$ sedang.

Cara yang dapat dilakukan untuk mencegah gejala komplikasi tersebut salah satunya dengan latihan kaki yaitu senam kaki (Singh et al., 2011). Latihan kaki dapat dipercaya untuk mengelola pasien yang mengalami DM tipe 2 (Widianti \& Proverawati, 2010). Senam kaki diabetes membantu meningkatkan sirkulasi darah dan memperkuat otototot kecil kaki (Colberg et al., 2010) dan mencegah terjadinya kelainan bentuk kaki, juga mengatasi keterbatasan jumlah insulin pada penderita DM tipe 2 (Zheng, Ley, \& Hu, 2017).
Sirkulasi darah pada daerah kaki dapat diukur melalui pemeriksaan non invasive pemeriksaan ankle brachial index (Thendria, Toruan, \& Natalia, 2014). Ankle Brachial Index (ABI) adalah metode sederhana dengan mengukur tekanan darah pada daerah ankle (kaki) dan brachial (tangan) (Pandya, Patel, \& Mahajan, 2016). Hasil pengukuran $\mathrm{ABI}$ menunjukkan keadaan sirkulasi darah pada tungkai bawah dengan rentang nilai sama atau lebih 0,90 menunjukkan bahwa sirkulasi ke daerah tungkai normal dan apabila kurang dari 0.90 dinyatakan sirkulasi ke kaki mengalami obstruksi. Nilai ini didapatkan dari hasil perbandingan tekanan sistolik pada daerah kaki dan tangan (Widyanthari, Ratna, \& Yulia, 2016).

Berdasarkan uraian diatas dapat dilihat masih banyak pasien diabetes yang mengalami masalah pada nilai ABI, oleh karena itu peneliti tertarik untuk mengadakan penelitian pengaruh senam kaki terhadap nilai ABI pada penderita DM tipe 2 di wilayah kerja Puskesmas Banjar II.

\section{METODE}

Desain penelitian menggunakan pre eksperimental dengan rancangan one group pre test post test design yaitu pengukuran/observasi dilakukan sebelum dan sesudah intervensi dimana rancangan ini tidak ada kelompok control) (Nursalam, 2015). Besar sampel sebanyak 54 responden yang mengalami DM tipe 2 tanpa komplikasi.

\section{HASIL}

Berdasarkan tabel 1 diketahui sebagian besar responden berjenis kelamin perempuan dan sebagian kecil berjenis kelamin laki-laki. Responden terbanyak berada pada rentang usia 45-55 tahun. 
Jurnal Ilmiah Keperawatan (Scientific Journal of Nursing), Vol 6, No 1, Tahun 2020

Sebagian besar responden mengenyam pendidikan SD.

(Putra, Md, et al, 2020) 
Tabel 1. Karakteristik Responden

\begin{tabular}{lcc}
\multicolumn{1}{c}{ Karakteristik } & $\mathrm{n}=54$ & $\%$ \\
\hline Jenis Kelamin & & \\
$\quad$ Perempuan & 28 & 51,9 \\
Laki-laki & 26 & 48,1 \\
Usia & & 42,6 \\
45-55 tahun & 23 & 38,9 \\
56-65 tahun & 21 & 18,5 \\
66-75 tahun & 10 & 9,3 \\
Pendidikan & & 556 \\
Tidak Sekolah & 5 & 35,2 \\
SD & 30 & 0 \\
SMP & 19 & 16,7 \\
BI sebelum diberikan senam kaki & & 48,1 \\
Noncompressible (>1,30) & 0 & 35,2 \\
Nilai ABI normal (0,90-1,30) & 9 & 0 \\
Penyakit vaskuler perifer ringan (0,7- & 26 & \\
0,89) & & 0 \\
Penyakit vaskuler perifer sedang (0,4- & 19 & 37,0 \\
0,69) & & 40,7 \\
Penyakit vaskuler perifer berat (0,40) & 0 & 22,2 \\
Nilai ABI sesudah diberikan senam kaki & & 0 \\
$\quad$ Noncompressible (>1,30) & 0 & \\
Nilai ABI normal (0,90-1,30) & 20 & \\
Penyakit vaskuler perifer ringan (0,7- & 22 & \\
0,89) & & \\
Penyakit vaskuler perifer sedang (0,4- & & \\
0,69) & & \\
Penyakit vaskuler perifer berat (0,40) & & \\
\hline
\end{tabular}

Tabel 2. Pengaruh Senam Kaki Terhadap Nilai Ankle Brachial Index (ABI)

\begin{tabular}{ccccc}
\hline Variabel & $\mathrm{N}$ & Mean \pm SD & Paired Different \\
& & & Perbedaan (Mean \pm & $\mathrm{P}$ \\
Pre Test & 54 & $0,76 \pm 0,11160$ & SD) & \\
Post Test & 54 & $0,80 \pm 0,10787$ & $0,039 \pm 0,085$ & 0,001 \\
\hline
\end{tabular}

Dilihat dari nilai ABI sebelum diberikan senam kaki sebagian besar responden berada pada kategori penyakit vaskuler perifer ringan, sebagian kecil menunjukkan hasil dengan nilai ABI normal. Setelah diberikan senam kaki, diketahui responden paling banyak yaitu dengan kategori penyakit vaskuler perifer ringan. Berdasarkan tabel 2 menunjukkan bahwa $p=0,001<\alpha=0,05$. Dengan demikian dapat disimpulkan bahwa "ada pengaruh senam kaki terhadap nilai ABI (ankle brachial index) pada penderita Diabetes Mellitus Tipe 2".

\section{PEMBAHASAN}

Sebagian besar responden yang menderita DM tipe 2 adalah perempuan. Wanita lebih berisko mengidap diabetes karena secara fisik wanita memiliki peluang peningkatan indeks masa tubuh yang lebih besar (Bintoro, Putra, Astriani, \& Dewi, 2019; Chatchawan, Eungpinichpong, Plandee, \& Yamauchi, 
2015). Sindroma siklus bulanan, dan pasca menopause yang membuat distribusi lemak tubuh mudah terakumulasi akibat proses penurunan fungsi hormon estrogen, penurunan pengeluaran hormon paratiroid dan meningkatnya hormon FSH dan LH (Sari, W, \& Sofiani, 2019) sehingga menimbulkan perubahan sistem pembuluh darah, sehingga wanita beresiko menderita DM tipe 2 (Trisnawati \& Setyorogo, 2013). Dengan demikian wanita yang beresiko dan mulai memasuki fase menopause agar lebih memperhatikan kesehatan agar terhindar dari penyakit DM.

Berdasarkan usia, responden usia tertinggi yaitu 74 tahun dengan kategori nilai ABI sedang. Semakin tua usia seseorang akan semakin beresiko menderita penyakit atau gangguan pada pembuluh darahb (Pratley, 2011). Hal tersebut disebabkan oleh penurunan intoleransi glukosa, adanya proses penuaan menyebabkan berkurangnya kemampuan sel $\beta$ pancreas dalam memproduksi insulin. (Trisnawati \& Setyorogo, 2013). Usia merupakan salah satu faktor yang mempengaruhi sirkulasi darah perifer (Association, 2019). Biasanya penyakit pada perifer banyak dialami pada orang yang lebih tua karena semakin bertambahnya usia maka fungsi organ akan semakin menurun.

Penelitian lain yang dilakukan oleh Tavip Dwi Wahyuni (2013) juga menunjukkan sebagian besar responden yang menderita DM tipe 2 berusia 51-60 tahun yaitu sebanyak 53,3\% (D. Wahyuni, 2013). Penyakit arteri perifer merupakan penyebab utama aterosklerosis perifer yang menyebabakan menurunnya sirkulasi darah pada kaki (Fareed, Salam, Khoja, Abdulrahman, \& Ahamed, 2017). Ditambah dengan semakin menuanya usia, fungsi organ juga semakin menurun, kebutuhan latihan fisik sering kali tidak terpenuhi dengan optimal maka dari itu banyak dari mereka dengan usia tua mengalami penyakit vaskuler perifer sedang.

Berdasarkan pendidikan, mayoritas lulusan SD sebanyak 30 orang $(55,6 \%)$. Tingkat pendidikan memiliki pengaruh terhadap kejadian DM tipe 2 (Chatchawan, Eungpinichpong, Plandee, \& Yamauchi, 2015). Orang yang tingkat pendidikannya tinggi biasanya akan memiliki banyak pengetahuan tentang kesehatan (Colberg et al., 2010). Dengan pengetahuannya tersebut orang akan memiliki kesadaran dalam menjaga kesehatan (Irawan, 2010). Dewasa ini penyakit tidak menular salah satunya DM tidak dilihat berdasarkan pendidikan, melainkan kebiasaan dan gaya hidup individu (Fareed et al., 2017). Ditambah dengan banyaknya komplikasi yang ditimbulkan oleh DM tipe 2 yaitu salah satunya penyakit vaskuler perifer, yang dapat dicegah dengan latihan fisik yang berkesinambungan.

Dilihat dari hasil pengamatan sebelum diberikan senam kaki, menunjukkan sebagian besar responden berada pada kategori penyakit vaskuler perifer ringan dengan rerata 0,76 . Sirkulasi darah kaki merupakan aliran darah yang dipompa jantung ke seluruh tubuh (Maeda, Inoguchi, Sasaki, \& Sonoda, 2014). Penurunan perfusi terberat adalah pada daerah distal atau kaki dan apabila keadaan ini berlangsung lama dapat menimbulkan komplikasi seperti PAD (Peripheral Arterial Disease) (A. Wahyuni \& Arisfa, 2016). Sirkulasi darah kaki merupakan aliran darah yang jauh dari pusat tubuh (jantung), apabila mengalami gangguan salah satu penyebabnya adalah kurangnya latihan fisik sehingga aliran darah pada kaki kurang lancar.

Sesudah diberikan senam kaki, ditemukan peningkatan hasil dengan rerata nilai $\mathrm{ABI}$ yaitu 0,80 . Latihan fisik efektif meningkatkan sirkulasi darah karena gerakan yang dihasilkan mampu lancarkan peredaran darah sehingga terjadi peningkatan nilai $\mathrm{ABI}$ sesudah 
diberikan latihan senam kaki. Peningkatan nilai ABI disebabkan karena pergerakan tungkai mengakibatkan menegangnya otot-otot pada tungkai dan menekan vena disekitar otot tersebut sehingga akan mendorong darah kearah jantung dan tekanan vena akan menurun. Mekanisme ini akan membantu melancarkan peredaran darah bagian kaki dan memperbaiki sirkulasi darah. Hasil rerata nilai $A B I$ sebelum diberikan tefrapi senam kaki yaitu 0,76 dan setelah diberikan intervensi senam kaki yaitu rerata nilai ABI menjadi 0,80. Penelitian ini membuktikan bahwa adanya pengaruh senam kaki terhadap nilai ABI pada penderita DM tipe 2 di wilayah kerja Puskesmas Banjar II. Hal ini didukung oleh penelitian yang dilakukan oleh Anggraini Sri Sulistyowati (2012) menunjukkan terdapat perbedaan yang signifikan antara kelompok eksperimen dan kelompok kontrol sebesar 0,000 $(\mathrm{p}<0,05)$ jadi dapat disimpulkan senam kaki efektif menurunkan kadar gula darah sewaktu pada penderita DM tipe 2, selain manfaat dari senam kaki yaitu dapat merelaksasi otot kaki dan melancarkan sirkulasi darah perifer (Yulita, Waluyo, \& Azzam, 2019), senam kaki juga mampu meningkatkan produksi insulin yang dipakai dalam transport glukosa ke sel sehingga membantu menurunkan glukosa dalam darah. (Sulistyowati, 2017). Senam kaki merupakan latihan yang sederhana dan efektif untuk meningkatkan sirkulasi pada daerah kaki dan mampu meningkatkan nilai ABI karena terjadi vasodilatasi pembuluh darah (Sari et al., 2019), sehingga dapat diterapkan khususnya pada penderita DM untuk mecegah terjadinya gangguan sirkulasi yang menimbulkan komplikasi salah satunya ulkus diabetik.

Senam kaki diabetik merupakan cara yang tepat untuk melancarkan sirkulasi terutama daerah kaki, karena gerakan kaki yang dilakukan selama senam kaki sama halnya dengan pijat kaki yaitu memberikan tekanan dan gerakan pada kaki, mempengaruhi hormon yaitu meningkatkan sekresi endorphin yang berfungsi menurunkan sakit (Fata, 2017), vasodilatasi pembuluh darah sehingga terjadi penurunan tekanan darah terutama sistolik brachialis yang berhubungan langsung dengan nilai ABI (A. Wahyuni $\&$ Arisfa, 2016). Dengan demikian senam kaki sangat dianjurkan untuk penderita DM untuk mencegah komplikasi yang ditimbulkan dari penyakit tersebut.

Dari penelitian yang dilakukan oleh peneliti menunjukkan bahwa, nilai ABI pada penderita DM tipe 2 di wilayah kerja Puskesmas Banjar II mengalami peningkatan setelah diberikan senam kaki, meskipun terdapat kesamaan kategori nilai ABI pada saat pretest dan posttest. Namun terdapat perbedaan jumlah yang signifikan sehingga hal ini dikatakan berhasil karena terapi yang diberikan sesuai dengan standar prosedur operasional senam kaki dan kerjasama antara penderita DM tipe 2 dan pemberi terapi di dalam proses peaksanaan pemberian intervensi.

\section{KESIMPULAN}

Berdasarkan hasil dari penelitian dan pembahasan, sehingga dapat ditarik kesimpulan sebagian besar responden berjenis kelamin perempuan, usia tertinggi yaitu 74 tahun dengan kategori nilai ABI sedang, mayoritas responden merupakan lulusan SD. Hasil rerata nilai ABI sebelum diberikan terapi senam kaki yaitu 0,76 dan setelah diberikan intervensi senam kaki yaitu menjadi 0,80 . Hasil uji statistik Paired T-Test, nilai signifikansi $0,001(\mathrm{p}<0,05)$ hal tersebut menunjukkan ada pengaruh senam kaki terhadap nilai Ankle Brachial Index (ABI) pada penderita DM tipe 2.

\section{DAFTAR PUSTAKA}

Association, A. D. (2019). 11 Microvascular Complications and Foot Care. In American Diabetes 
Association (Vol. 42, pp. 124-138).

USA. https://doi.org/10.2337/dc19S011

Bintoro, T., Putra, M. M., Astriani, N. M.

D. Y., \& Dewi, P. I. S. (2019). Illness

Perception, Motivation, and SelfCare Behavior in Diabetic Patients. In Promoting Population Mental Health and Well-Being (pp. 236236). Masters Program in Public Health, Universitas Sebelas Maret. https://doi.org/10.26911/theicph.201 9.02.46

Chatchawan, U., Eungpinichpong, W., Plandee, P., \& Yamauchi, J. (2015). Effects of Thai Foot Massage on Balance Performance in Diabetic Patients with Peripheral Neuropathy: A Randomized Parallel-Controlled Trial. Medical Science Monitor Basic Research, 21, 68-75. https://doi.org/10.12659/MSMBR.8 94163

Colberg, S. R., Sigal, R. J., Fernhall, B., Regensteiner, J. G., Bussmer, B. J., Rubin, R. R., ... Braun, B. (2010). Exercise and Type 2 Diabetes. The American College of Sports Medicine and The American Diabetes Association, pp. 2692-2696. https://doi.org/10.2337/dc10-1548

Fareed, M., Salam, N., Khoja, A. T., Abdulrahman, M., \& Ahamed, M. (2017). Life Style Related Risk Factors of Type 2 Diabetes Mellitus and Its Increased Prevalence in Saudi Arabia. International Journal of Medical Reseacrh \& Health Sciences, 6(3), 125-132.

Fata, U. H. (2017). Overview Of Ankle Brachial Index (ABI) Value On Diabetes Mellitus Type 2 In Blitar. Jurnal Ners Dan Kebidanan, 4(3), 254-259.

Fatimah, R. N. (2015). Diabetes Melitus Tipe 2. Journal Majority, 4, 93-101. Irawan, D. (2010). Thesis Faktor Risiko Kejadian Diabetes Mellitus Tipe 2 di Daerah Urban Indonesia. Universitas Indonesia.
Kemenkes. (2018). Prevalensi Diabetes Mellitus di Indonesia 2018. In Riset Kesehatan Dasar. Jakarta.

Maeda, Y., Inoguchi, T., Sasaki, S., \& Sonoda, N. (2014). Brachial-Ankle Pulse Wave Velocity Predicts AllCause Mortality and Cardiovascular Events in Patients With Diabetes: The Kyushu Prevention Study of Atherosclerosis. Diabetes Care, 37(August), 2383-2390. https://doi.org/10.2337/dc13-1886

Nursalam. (2015). Metodologi Penelitian Pendekatan Praktis (4th ed.). Jakarta: Salemba Medika.

Pandya, J., Patel, K., \& Mahajan, N. (2016). Ankle Brachial Index (ABI). International Journal of Basic and Applied Physiology, 5(12), 1-5.

Pratley, R. E. (2011). The Early Treatment of Type 2 Diabetes. The American Journal of Medicine, 126(9), S2-S9. https://doi.org/10.1016/j.amjmed.20 13.06.007

Sari, A., W, A. W., \& Sofiani, Y. (2019). Efektivitas Perbandingan Buerger Allen Exercise dan Senam Kaki Terhadap Nilai ABI Pada Penderita DM Tipe 2. Journal Of Telenursing, 1, 1-16.

Singh, P. P., Dawn Abbott, J., Lombardero, M. S., Woodhead, G., Venkitatchalam, L., Tsapatsaris, N. P., ... Nesto, R. W. (2011). The Prevalence and Predictors of an Abnormal Ankle-Brachial Index in the Bypass Angioplasty Revascularization. Brief Report Group, 34, 3-6. https://doi.org/10.2337/dc10-1734

Sulistyowati, A. S. (2017). Thesis Pengaruh Senam Kaki Terhadap Kadar Gula darah Sewaktu Pada Penderita Diabetes Melitus Tipe II Di Wilayah Kerja Puskesmas Cawas 1. Unisa Digital. Universitas Aisyiyah Yogyakarta.

Thendria, T., Toruan, I. L., \& Natalia, D. (2014). Hubungan antara Hipertensi dan Penyakit Arteri Perifer 
Berdasarkan Nilai Ankle-Brachial Index. EJournal Kedokteran Indonesia, 2(1).

Trisnawati, S. K., \& Setyorogo, S. (2013).

Faktor Risiko Kejadian Diabetes Melitus Tipe II Di Puskesmas Kecamatan Cengkareng Jakarta Barat Tahun 2012. Jurnal Ilmiah Kesehatan, 5(1), 6-11.

Wahyuni, A., \& Arisfa, N. (2016). Senam Kaki Diabetik Efektif Meningkatkan Ankle Brachial Index Pasien Diabetes Melitus Tipe 2. Jurnal Ipteks Terapan, 9.i2, 155-164.

Wahyuni, D. (2013). Ankle brachial index sesudah senam kaki diabetes pada penderita diabetes melitus tipe 2 . Jurnal Keperawatan, 4, 143-151. https://doi.org/10.1109/ULTSYM.20 06.112

WHO. (2016). Diabetes Fakta dan Angka. Searo. Jakarta.

Widianti, A. T., \& Proverawati, A. (2010). Aplikasi Senam Untuk Kesehatan -
Senam Kesehatan -. Yogyakarta: Mulia Medika.

Widyanthari, D. M., Ratna, S., \& Yulia. (2016). Pemeriksaan Ankle Brachial Index (ABI) Post Exercise Pada Pasien Diabetes Melitus Dengan Peripheral Arterial Disease. Jurnal Keperawatan Community of Publishing in Nursing, (April), 1823.

Yulita, R. F., Waluyo, A., \& Azzam, R. (2019). Pengaruh Senam Kaki Terhadap Penurunan Skor Neuropati dan Kadar Gula Darah Pada Pasien Dm tipe 2. Journal of Telenursing, 1, 80-95.

Zheng, Y., Ley, S. H., \& Hu, F. B. (2017). Global aetiology and epidemiology of type 2 diabetes mellitus and its complications. Nature Reviews Endocrinology, 14(2), 88-98. https://doi.org/10.1038/nrendo.2017. 151 